\title{
ENERGY LOSS AND CONSUMPTION DEVIATION ANALYSIS OF 1000MW ULTRA SUPER CRITICAL STEAM TURBINE UNIT ON OFF-DESIGN CONDITION
}

\author{
Tian-jing Fan, Nian-su Hu, Di Guo, Mei Huang \\ School of Power \& Mechanical Engineering, Wuhan University, Wuhan, China
}

\begin{abstract}
In this paper, the operating economy of the 1000MW USC (Ultra Super Critical) steam turbine unit is studied by the energy loss and heat consumption deviation analysis. The heat economy calculation model is built by using the conventional heat balance method and the equivalent enthalpy drop method, and the key parameters on off-design condition are determined, which ensure the accuracy of the results of the energy loss and heat consumption deviation analysis. For some special conditions which are not suitable for the equivalent enthalpy drop method, the off-design condition calculation of the steam turbine and its thermal system is adopted.
\end{abstract}

Keywords: Steam turbine unit, Energy losses analysis, Off-design condition, Target value, Coefficients of heat consumption deviation

\section{INTRODUCTION}

Energy loss and heat consumption deviation analysis of the thermal system of the steam turbine is the base of designing and developing a performance detection system for steam turbine units, which can detect the operating condition of the steam turbine-units on-line and help the power plants know clearly their real-time operating costs. So, energy loss and heat consumption deviation analysis has been considered to be an effective approach to improve the economical efficiency of the steam turbine units. Normally, in the power network, large capacity steam turbine units operated at basic load, and the efforts were focused on their operational economics on rated conditions. Along with the rapid growth of the power network capacity, more and more large capacity steam turbine units are required to participate in the regulation of the power network. Accordingly, it is necessary to carry forward the research on their operational economics on off-design condition.

This paper tries to study the operating economy of the $1000 \mathrm{MW}$ USC (Ultra Super Critical) steam turbine unit by energy loss and heat consumption deviation analysis. Firstly, use the conventional heat balance method and the equivalent enthalpy drop method to build the heat economy calculation model of the $1000 \mathrm{MW}$ USC steam turbine unit. Then, on the base of the model and its calculation results, determine the key parameters (the target values and the coefficients of heat consumption deviation) of the unit on off-design condition. Consequently, the results of the energy loss and heat consumption deviation analysis are accurate enough to satisfy the need of the unit to operate economically at both full and partial load. In addition, for some special conditions such as the failure of the auxiliary equipments, perform the off-design condition calculation of the steam turbine and its thermal system.

Copyright $\odot 2009$ by the Japan Society of Mechanical Engineering

\section{BUILDING OF THE HEAT ECONOMY CALCULATION}

The building of the heat economy calculation model of the $1000 \mathrm{MW}$ USC steam turbine unit is based on the conventional heat balance method and the equivalent enthalpy drop method.

\subsection{The Initial Condition}

The initial condition of the energy loss and heat consumption deviation analysis includes the basic operating parameters of the unit on four typical loads $(100 \%, 75 \%$, $50 \%, 30 \%$ THA). Generally, they are the pressure and temperature of the steam and water in the thermal systems of the steam turbine, which are the input values of the conventional heat balance calculation.

\subsection{Results of the Conventional Heat Balance Calculation}

By the conventional heat balance method, the main heat economic indicators (the internal efficiency of the steam turbine unit $\eta_{i}$ and the coal consumption rate $b_{b}$ ) on the four typical loads can be obtained, as shown in table 1 .

Table 1 The main heat economic indicators

\begin{tabular}{lcccc}
\hline Load & $100 \%$ & $75 \%$ & $50 \%$ & $30 \%$ \\
\hline$\eta_{\mathrm{i}}(\%)$ & 50.032 & 49.323 & 47.815 & 45.176 \\
\hline $\mathrm{b}_{\mathrm{b}}$ & 275.41 & 279.37 & 288.18 & 305.02 \\
$(\mathrm{~g} / \mathrm{kW} \times \mathrm{h})$ & & & & \\
\hline
\end{tabular}

\subsection{Results of the Equivalent Enthalpy Drop Calculation}

By the equivalent enthalpy drop method, we can get the equivalent enthalpy drop of the live steam $H$, and the equivalent enthalpy drops $H_{j}$ and efficiencies $\eta_{j}$ of the extraction steams of the steam turbine.

With the varying of one of the operating parameters, the equivalent enthalpy drop of the live steam and the heat absorption of the cycle change, and the changed values are 
expressed as $H^{\prime}=H+\Delta H$ and $Q^{\prime}=Q+\Delta Q$ respectively. The changed internal efficiency of the steam turbine unit is defined as

$$
\eta_{i}^{\prime}=\frac{H^{\prime}}{Q^{\prime}}
$$

and the relative change of it can be worked out:

$$
\delta \eta_{i}=\frac{\eta_{i}^{\prime}-\eta_{i}}{\eta_{i}^{\prime}}=\frac{\frac{H^{\prime}}{Q^{\prime}}-\frac{H}{Q}}{\frac{H^{\prime}}{Q^{\prime}}}=\frac{\Delta H-\Delta Q \eta_{i}}{H+\Delta H}
$$

Consequently, the increase of the coal consumption rate can be figured out:

$$
\Delta b_{b}=b_{b} \delta \eta_{i}
$$

where $b_{b}$ : the initial coal consumption rate.

\subsection{Examples of the Heat Consumption Deviation Analysis}

According to the principle, calculate and analyze the energy losses causing by the influencing factors. Here are two examples: the curves in Fig. 1 show the relationship between the increase of the pressure losses of the No.1 4 extraction steam and the increase of the coal consumption rate, and the curves in Fig. 2 show the relationship between the increase of the terminal temperature differences of the No.1 3 high pressure heater and the increase of the coal consumption rate.

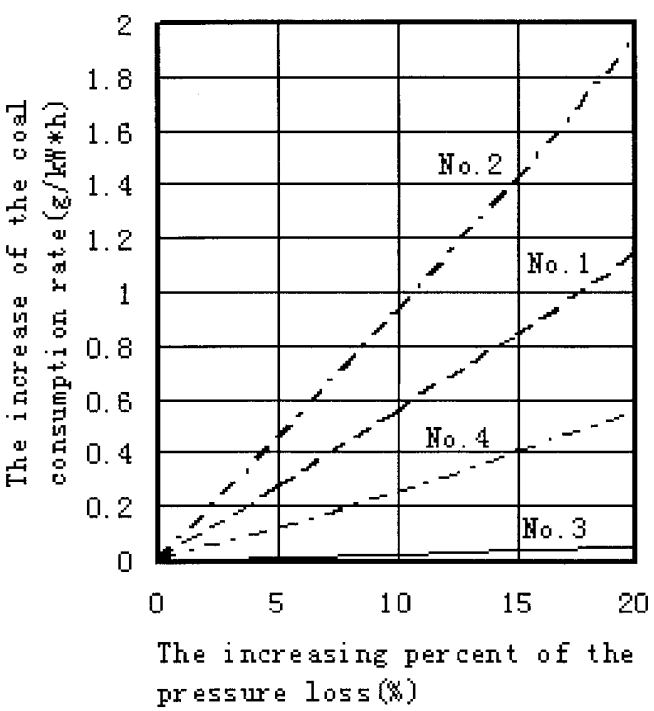

Figure 1 The energy loss causing by the pressure losses of the No.1 4 extration steam

\section{DETERMINATION OF THE KEY PARAMETERS ON OFF-DESIGN CONDITION}

The principle of energy loss and heat consumption deviation analysis of the thermal system of the steam turbine is based on the fact that the operational economics of steam turbine-units depend on the approach degree between real-time operating parameters and the target values. Accordingly, the accuracy of the coefficients of heat consumption deviation and the target values determines the accuracy and reliability of the results of energy loss and accuracy and reliability of the results of energy loss and heat consumption deviation analysis. Presently, large capacity steam turbine units are frequently required to regulate their loads, and the target values under the part loads are different from that under the rated load and vary with the running load.

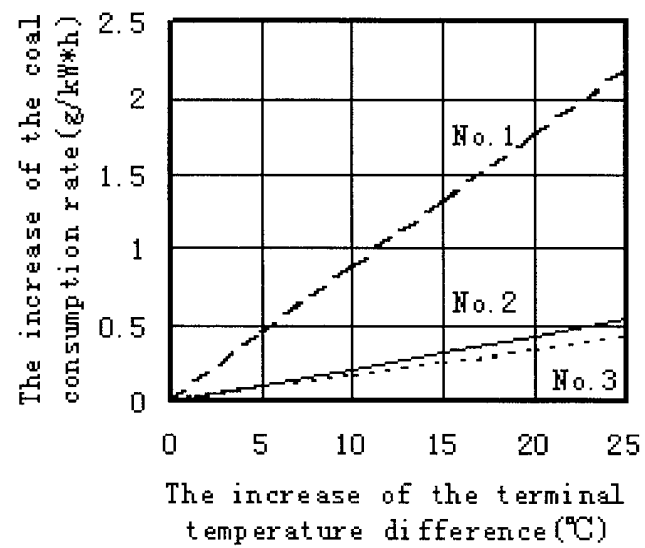

Figure 2 The energy loss causing by the terminal temperature differences of the No.1 3 heaters

\subsection{The Target Values}

The calculation of the target values on the off-design condition of turbine is based on the steam and water parameters on four loads ( $100 \%, 75 \%, 50 \%$ and $30 \%$ THA) from the steam turbine heat balance diagrams. The calculating method is fitting the relationship curve between the target value and the load by corrected minimum secondary fitting method, which has been inspected to be precise enough.

The fitting curve can be expressed as a secondary curve $S(x)=a x^{2}+b x^{2}+c$, where $a, b, c$ are unknown, and $x$ is the load of the unit. According to the condition

$$
R=\sum_{i=0}^{m}\left[S\left(x_{i}\right)-y_{i}\right]=\min , i=1,2,3,4
$$

$[a, b, c]^{r}$ can be worked out by matrix method.

$$
\text { Setting } z_{i}=1 / 2\left(x_{i}+x_{i+1}\right) \text {, in reference to }
$$

$S_{i}(x)=a_{i} x^{2}+b_{i} x+c_{i}, \quad i=1,2,3$, and a equation follows as

$$
\left[\begin{array}{c}
S\left(x_{i}\right) \\
S\left(z_{i}\right) \\
S\left(x_{i+1}\right)
\end{array}\right]=\left[\begin{array}{ccc}
x_{i}^{2} & x_{i} & 1 \\
z_{i}^{2} & z_{i} & 1 \\
x_{i+1}^{2} & x_{i+1} & 1
\end{array}\right]\left[\begin{array}{c}
a_{i} \\
b_{i} \\
c_{i}
\end{array}\right]
$$

Working out $\left[a_{i}, b_{i}, c_{i}\right]^{T}$, then the correction curve can be shown as

$$
S_{i}(x)=a_{i} x^{2}+b_{i} x+c_{i} \quad x_{i} \leq x<x_{i+1}, \quad i=1,2,3
$$

With the corrected fitting curve, not only the tendency of the former curve can be maintained, but also 
the ends can be kept exactly on the curve. It successfully avoids the abnormal error in actual energy loss calculation.

\subsection{The Coefficients of Heat Consumption Deviation}

The principle of the coefficients of heat consumption deviation of the parameters is the equivalent enthalpy drop method. Firstly, get the coefficients of heat consumption deviation by the equivalent enthalpy drop calculation on four loads $(100 \%, 75 \%, 50 \%$ and $30 \%$ THA). Then, set the maximum and minimum deviation of the parameter as the initial values of energy loss calculation. Thus the calculation model of the heat consumption augment can be built, which is related to both the load and the deviation of the parameter.

The maximum range of the parameter is set as $[0, \Delta x]$, and it is divided into $N$ spans. Thus the deviation marked as $j$ is

$$
\Delta x_{j}=j \Delta X / N \quad j=1,2, \ldots, N
$$

Its corresponding heat consumption augment is expressed as

$$
D_{i j}=f\left(p_{i}, \Delta x_{j}\right)
$$

where $D_{i j}$ : the heat consumption augment when the load is $p_{i}$ and the deviation is $\Delta x_{j}$, and $f(0$ : the calculation model of the heat consumption augment.

If $p_{i} \leq p_{s}<p_{i+1} \quad\left(p_{s}\right.$ is the actual load) and $\Delta x_{j} \leq \Delta x_{s}<\Delta x_{j+1}$ ( $\Delta x_{s}$ is the actual deviation), the actual heat consumption augment ${ }^{D_{s}}$ can be gained by twice linear interpolation, which is simple calculation.

\section{ENERGYLOSS ANALYSIS ON AUXILIARY EQUIPMENT FAILURE CONDITION}

The precondition of using the equivalent enthalpy drop method is that the flow of the live steam is basically steady. When one or several heaters are shutdown because of fault, the corresponding extraction steams are out of service, which results in the change of the thermal process of the steam turbine. On these special conditions, the equivalent enthalpy drop method cannot be employed. Facing the problem, we introduce the off-design condition calculation of the steam turbine and its thermal system, and perform the energy loss and heat consumption deviation analysis on three loads ( $100 \%, 75 \%$ and $50 \%$ THA). Hence, the curves of the increase of the coal consumption rate can be gotten.

Here are two of the heater failure conditions: the curve in Fig. 3 shows the increase of the coal consumption rate on various loads when all of the three high pressure heaters are shutdown (In the thermal system of the $1000 \mathrm{MW}$ USC steam turbine unit, the three high pressure heaters share a by-pass, so they had to be shutdown together when one of them breaks down), and the curve in Fig. 4 shows the increase of the coal consumption rate on various loads when No.6 low pressure heater is shutdown (The No.5 and No.6 low pressure heaters in the system have their own by-passes, so they can be shutdown respectively when one of them breaks down ).

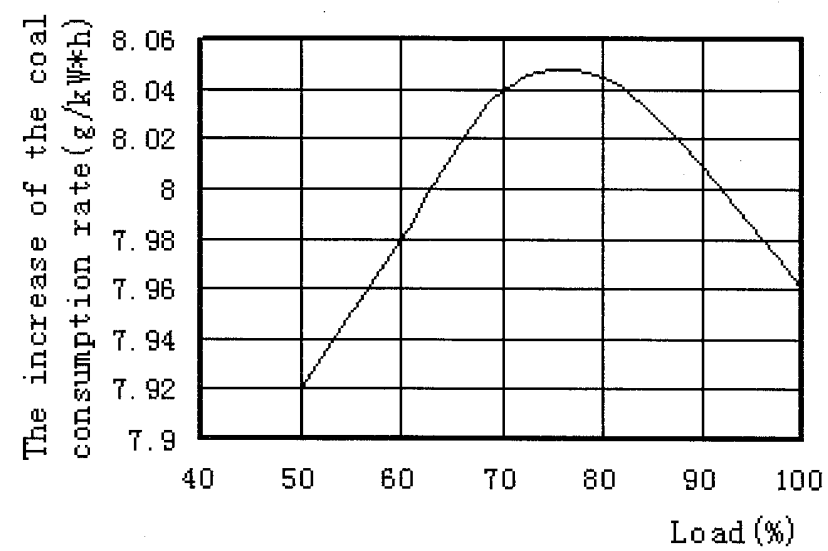

Figure 3 The energy loss causing by shutdown of No.1 3 heaters.

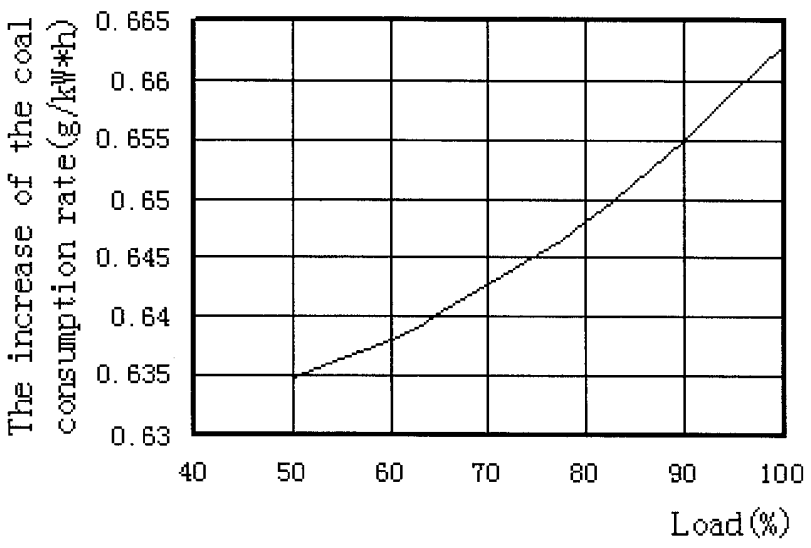

Figure 4 The energy loss causing by shutdown of No.6 heaters.

\section{CONCLUSION}

Energy loss and heat consumption deviation analysis of the 1000MW USC steam turbine unit on off-design condition guarantees the accuracy of the operating economy results and meets the demand of the flexibility and economy of the unit. Furthermore, the results can provide a firm basis for the development of a performance detection system for steam turbine units.

\section{REFERENCES}

1. Hu Nian-su, Guo Qiang, Sheng Li and Fan Tian-jing, Energy Loss Detection System of A 300MW Steam Turbine Set Based on $\mathrm{C} / \mathrm{S}$ Structure, Power Engineering, 22(04) (2002), pp.1888-1892.

2. Guo Qiang, $\mathrm{Hu}$ Nian-su and Fan Tian-jing, Energy Loss Monitoring System Based on MIS in the Power Plant, Turbine Technology, 43(06) (2001), pp.371-374.

3. Chen Hong-wei, Li Xiao-jin, Zhen Zhi, Zhang Hua and Li Yong-hua, Modular Design and Application of the Energy-loss Analysis in Power Unit Based on B/S, Power System Engineering, 20(03) (2004), pp.38-40.

4. Hu Nian-su, Huangfu Ya-fei, Zhao Yu and Hu Sheng, Virtual Sensor of the Steam Turbine Unit Analysis and Diagnosis System and Its Input Parameter Optimization, Proc. of Int. Conf. on Power 
Engineering 2003 (ICOPE-03), (2003).

\section{NOMENCLATURE}

$b_{b} \quad$ The coal consumption rate, $\mathrm{g} /(\mathrm{kWh})$

$H$ The equivalent enthalpy drop of the live steam, $\mathrm{kJ} / \mathrm{kg}$

$H_{j} \quad$ The equivalent enthalpy drops of the extraction steams of the steam turbine, $\mathrm{kJ} / \mathrm{kg}$
$Q \quad$ The heat absorption of the cycle change, $\mathrm{kJ} / \mathrm{kg}$

$\eta_{i}$ The internal efficiency of the steam turbine unit, \%

$\eta_{j}$ The efficiency of the extraction steams of the steam turbine, $\%$ 